\title{
Variation in Speciation and Availability of Phosphorus in Paddy Soil
}

\author{
Shinji Sakurai' ${ }^{1}$, Yasuaki Nishiura ${ }^{2}$, Haruhiko Horino ${ }^{1}$, Takao Nakagiri1 \\ ${ }^{1}$ Graduate School of Life and Environmental Sciences, Osaka Prefecture University, Sakai-city, Japan \\ ${ }^{2}$ Sumitomo Mitsui Banking Corporation, Himeji-city, Japan \\ Email: sakurai@envi.osakafu-u.ac.jp
}

How to cite this paper: Sakurai, S., Nishiura, Y., Horino, H. and Nakagiri, T. (2018) Variation in Speciation and Availability of Phosphorus in Paddy Soil. Open Journal of Soil Science, 8, 213-224. https://doi.org/10.4236/ojss.2018.89017

Received: July 31, 2018

Accepted: August 31, 2018

Published: September 4, 2018

Copyright (c) 2018 by authors and Scientific Research Publishing Inc. This work is licensed under the Creative Commons Attribution International License (CC BY 4.0).

http://creativecommons.org/licenses/by/4.0/

(c) (i) Open Access

\begin{abstract}
There is a global concern about the depletion in phosphorus $(\mathrm{P})$ resources in the near future. Some attempts for effective reuse of $\mathrm{P}$, including recovery from municipal wastes, have been conducted. However, a strong sorption of $\mathrm{P}$ onto some minerals may result in low $\mathrm{P}$ availability for crops. Therefore, it is necessary to understand the speciation of the chemical forms of $\mathrm{P}$ and to elucidate the relationships between $\mathrm{P}$ availability and chemical forms of $\mathrm{P}$ in soil. This study focuses on the variation in $\mathrm{P}$ speciation and the chemical forms of available $\mathrm{P}$ in a paddy soil. Incubation experiments with/without drainage, simulating the situation in a paddy field, were performed at a laboratory scale to evaluate the variation in speciation and $\mathrm{P}$ availability in soil. The speciation of $\mathrm{P}$ was analyzed according to Wilson's sequential extraction method and measured using Bray No. 2 and Truog methods. Two kinds of chemical forms, i.e., Fe and $\mathrm{Mn}$ (oxy)hydroxides (Fe-Mn-P) and organic and biogenic $\mathrm{P}$ (Org-P) were predominant in the soil, and they were easily interconverted by changing soil redox conditions. Available P using the Bray No. 2 method was increased in 21 days owing to the anaerobic condition; thereafter, it reached a constant value by the end of both the incubation experiments. However, a drastic decrease was detected in available P, using Truog-P. It occurred owing to the drying of soil, which suggested that some chemical form(s) of $\mathrm{P}$ other than Truog-P might be generated. A comparison between the concentrations of available $\mathrm{P}$ and that of each chemical form showed that available $\mathrm{P}$ included some Org- $\mathrm{P}$, which might be less absorbed by plants compared to the exchangeable and pore water fraction (Ex-P) and Fe-Mn-P. We conclude that anaerobic soil conditions play an important role in the efficient consumption of $\mathrm{P}$.
\end{abstract}

\section{Keywords}

Phosphorus, Availability, Chemical Form, Sequential Extraction, Incubation 
Experiment

\section{Introduction}

Phosphorus (P) is essential for plant growth and crop productivity. For the development of cropping systems, a large amount of $\mathrm{P}$ is applied to agricultural lands [1]. However, there is an increasing global concern that $\mathrm{P}$ resources will be depleted in a few decades because of the limited $\mathrm{P}$ resources (e.g., phosphate rock) [2]. In addition, an undesirable loss of $P$ from agricultural fields due to runoff during agricultural management and heavy rainfalls may lead to surface water eutrophication [3] [4]. These worries regarding $P$ have boosted research in order to retain and/or remove excess $\mathrm{P}$ through processes including assimilation, sorption, and chemical precipitation [5]. In order to mitigate the harmful effects of $\mathrm{P}$ addition on agriculture and environment, efficient consumption of $\mathrm{P}$ by vegetation within soil seems to be one of the most effective solution strategies. Once P is applied to the soil, $\mathrm{P}$ is likely to have low solubility, and to be converted quickly into insoluble and immobile forms, resulting in growth limitation [6]. Therefore, water and soil management is necessary for $\mathrm{P}$ application into soil for maintaining chemical forms available to plants and crops.

Since long, many studies have aimed to identify and evaluate the chemical forms of $\mathrm{P}$ available to plants (e.g., Olsen and Sommers [7], Kuo [8]). Chang and Jackson [9] summarized the extractability of various kinds of phosphates (e.g., aluminum phosphate, iron phosphate, calcium phosphate) using several extractants (e.g., sulfuric acid, ammonium fluoride, and sodium hydroxide). Moreover, the relationship between the chemical forms and the availability of $\mathrm{P}$ has been investigated by several researchers [1] [10]. However, the understanding on these relationships is inadequate until date, because the mechanisms involving soil $\mathrm{P}$ by plant uptake are extremely complex.

In paddy fields, some drastic changes in the soil redox condition occur during the cropping period owing to water management for rice growth, which may alter the speciation and availability of $\mathrm{P}$ in soil. Therefore, the consumption of $\mathrm{P}$ in soil by rice cropping could be less efficient than that in other crops due to the changing chemical forms of $\mathrm{P}$. It is important to elucidate the fluctuation in the status of $\mathrm{P}$ in paddy fields. However, there have been few studies on the transition of chemical forms and availability of $\mathrm{P}$ owing to the changes in the soil redox status.

The aim of this study was to elucidate the effects of the changes in the soil redox condition on the chemical properties of $\mathrm{P}$ by observing the chemical forms of $\mathrm{P}$ present in the soil, based on two incubation experiments. The findings of this study were expected to be useful for controlling the soil and watering conditions with the aim of promoting the efficient consumption of P. Moreover, this study was expected to provide valuable information on the identification of 
chemical forms of available $\mathrm{P}$.

\section{Materials and Methods}

Simulating the situation in a paddy field, two different incubation experiments (with or without drainage) were performed separately on a laboratory scale to evaluate the speciation and the availability of $\mathrm{P}$ in soil. An experiment was conducted without drainage, i.e., under submerged conditions throughout the incubation period. The other experiment allowed drainage within the study period. The soil in this study was sampled from a paddy field at a depth of $0-15$ $\mathrm{cm}$ in the lowland around Lake Biwa in Shiga Prefecture of Japan on October 29, 2015, after rice harvest. The sampling point was located within in approximately $1 \mathrm{~km}$ from the lake shore. The soil was prepared for incubation experiments by air-drying and sieving with a $2-\mathrm{mm}$ sieve. The soil type was classified as gley lowland soil. Physical and chemical properties of the soil are shown in Table 1.

\subsection{Reagent Quality}

All the chemicals used, except sodium hydrosulfite, were of Japan Industrial Standard special grade or better, purchased from Wako Pure Industries Ltd. (Osaka, Japan). Sodium hydrosulfite was of Japan Industrial Standard chemical pure grade.

\subsection{Incubation Experiments}

In the incubation experiment without drainage, $40 \mathrm{~g}$ dry-soil was filled into a $110 \mathrm{~mL}$ screw glass bottle, and was submerged with distilled water in the screw bottle up to a depth of $7 \mathrm{~cm}$ during the incubation period. Flooding water and soil were sampled after $1,3,7,14,21,28,35,42$, and 63 days from the onset of treatment for the evaluation of the speciation and availability of P. In addition, oxidation-reduction potential (ORP) in the soil during the incubation period was measured with the reference electrode in saturated $\mathrm{KCl}$ solution (IM-32P, TOA DDK Co., Tokyo, Japan) in order to evaluate the soil redox status. The values of ORP in saturated $\mathrm{KCl}$ solution were approximately converted into those of ORP with standard hydrogen electrode (Eh) using Equation (1), by correcting for the electrode potential of the reference electrode. (Matsushita et al. [11]):

Table 1. Physical and chemical properties of paddy soil used in this study.

\begin{tabular}{cc}
\hline Property & Means \pm standard deviation $(\mathrm{n}=3)$ \\
\hline Soil particle density $\left(\mathrm{g} / \mathrm{cm}^{3}\right)$ & $2.46 \pm 0.01$ \\
$\mathrm{pH}\left(1: 5 \mathrm{H}_{2} \mathrm{O}\right)$ & $5.5 \pm 0.14$ \\
$\mathrm{EC}\left(1: 5 \mathrm{H}_{2} \mathrm{O}\right)(\mu \mathrm{S} / \mathrm{cm})$ & $149 \pm 33$ \\
$\mathrm{CEC}\left(\mathrm{cmol}_{\mathrm{c}} / \mathrm{kg}\right.$ dry-weight $)$ & $15.8 \pm 0.07$ \\
Ignition loss $(\%)$ & $8.07 \pm 0.10$
\end{tabular}




$$
\mathrm{Eh}=\mathrm{ORP}+206 .
$$

In the incubation experiment with drainage, soil was submerged with distilled water for the first 35 days of incubation. Thereafter, the water was removed, and the soil was left unsubmerged for 14 days. The soil was again submerged with distilled water and stored by the end of the experiment (i.e., after 70 days of the incubation started). The duration of the incubation experiment was 70 days with sampling at days $7,21,35,42,49,56,63$, and 70 days. Both incubation experiments were conducted at room temperature $\left(20^{\circ} \mathrm{C}-25^{\circ} \mathrm{C}\right)$ in triplicates.

\subsection{Sequential Extraction of the Chemical Forms of $\mathbf{P}$}

One gram of wet soil was analyzed for fractionating $\mathrm{P}$ in chemical forms according to the sequential extraction method developed by Wilson et al. [12], as illustrated in Figure 1, which was the modified sequential extraction procedure of Psenner et al. [13]. According to Wilson et al. [12], P is chemically partitioned into five fractions: in order of mobility: 1) the loosely sorbed, exchangeable, and pore water fraction (Ex-P), 2) the reducible fractions, primarily $\mathrm{Fe}$ and $\mathrm{Mn}$ (oxy)hydroxides and associated $\mathrm{P}$ (Fe-Mn- $\mathrm{P}), 3$ ) some $\mathrm{Al}$ and $\mathrm{Fe}$ (oxy)hydroxides and associated $\mathrm{P}$, as well as some organic and biogenic $\mathrm{P}$ (Org- $\mathrm{P}), 4) \mathrm{P}$ in acid-soluble minerals (Min-P), and 5) $\mathrm{P}$ in residual material (Res-P). Concentrations of $\mathrm{P}$ in each of the fractions were determined with the ultraviolet and visible spectrophotometer (UV-1800, Shimadzu, Kyoto, Japan) according to the molybdate-blue spectrophotometric method.

\subsection{Measurement of Available P}

Two different indices commonly used as available $\mathrm{P}$ in paddy soils in Japan were used in order to investigate the fluctuation of the availability as well as chemical forms of $\mathrm{P}$ accompanied by the change in the soil redox condition. One index

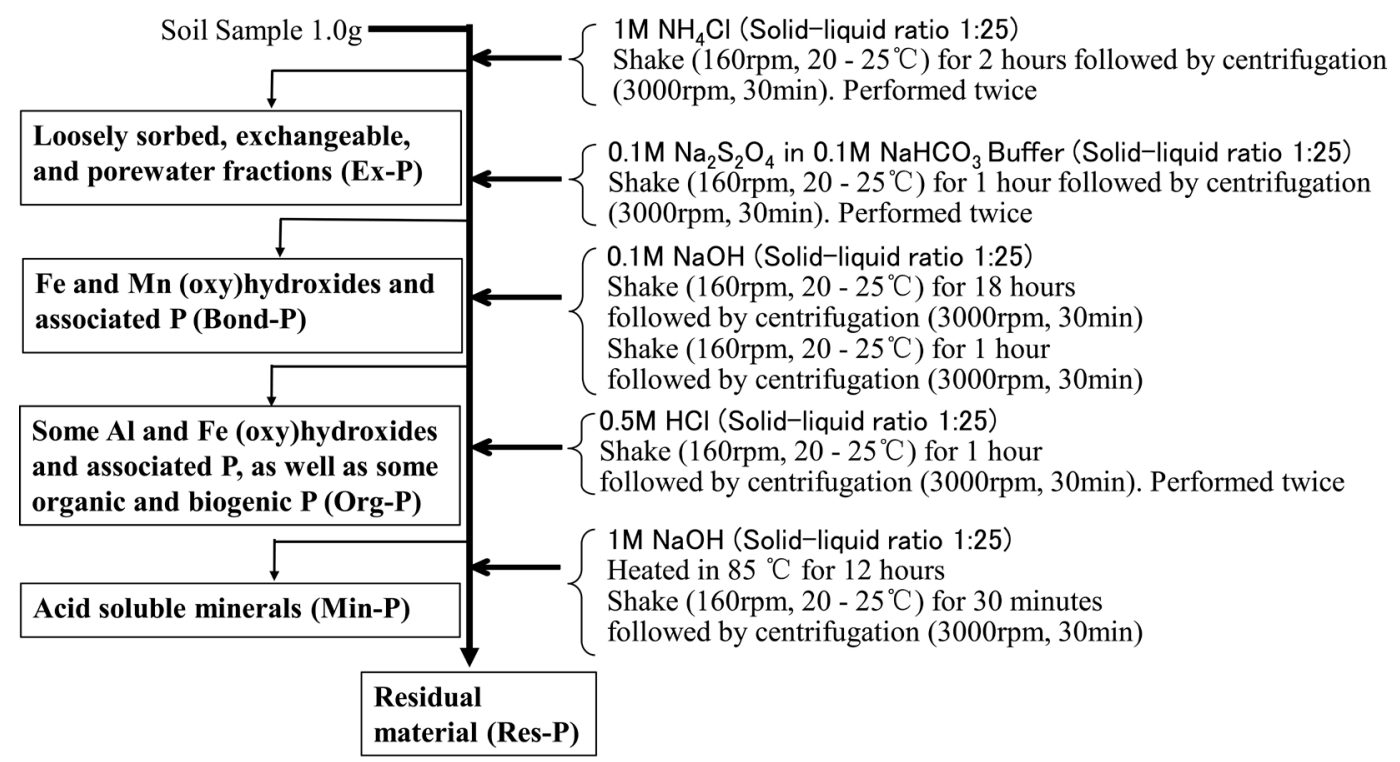

Figure 1. Procedure sequential P extraction of Wilson et al. 
(Bray2-P) was measured according to the Bray No. 2 method [14], whereas the other (Truog-P) was measured by the Truog method [15]. The former method was modified according to the properties of Japanese soil [16]. A brief description of these procedures in the two methods is given in Table 2.

\subsection{Measurement of $P$ in the Water Used for Flooding}

$\mathrm{P}$ concentrations in the water used for flooding were evaluated as total $\mathrm{P}(\mathrm{T}-\mathrm{P})$ in order to observe leaching or precipitation, and fluctuation of the chemical forms of $\mathrm{P}$ in the soil. In the pretreatment of T-P, $20 \mathrm{~mL}$ of the water sample was autoclaved at $120^{\circ} \mathrm{C}$ for 30 min with $\mathrm{K}_{2} \mathrm{~S}_{2} \mathrm{O}_{8}$. The T-P concentration was measured by the spectrophotometric ammonium molybdate-blue method. In addition to T-P, dissolved P (D-P) concentration was determined by filtering the water sample with 5C quantitative ashless filter paper (ADVANTEC, Tokyo, Japan) before autoclaving. Moreover, particulate $\mathrm{P}(\mathrm{P}-\mathrm{P})$ was estimated as the difference between T-P and D-P.

\subsection{Measurement of Fe in the Water Used for Flooding}

Total Fe concentrations (T-Fe) in the flooding water was measured in order to understand the behavior of Fe; T-Fe plays an important role in determining the behavior of $\mathrm{P}$ in the environment, including adsorption, eluviation, and precipitation [17]. Ten milliliters of the water used for flooding was sampled using a 15 $\mathrm{mL}$ centrifuge tube. This sample was digested by heating at $120^{\circ} \mathrm{C}$ for $60 \mathrm{~min}$ with $0.5 \mathrm{~mL}$ of $60 \% \mathrm{HNO}_{3}$ in the pretreatment of T-Fe measurement. Similar to the concentrations of $\mathrm{P}$, the concentrations of dissolved $\mathrm{Fe}(\mathrm{D}-\mathrm{Fe})$ were determined by filtering the water used for flooding with $5 \mathrm{C}$ quantitative ashless filter paper (Advantec, Tokyo, Japan) before digestion with $\mathrm{HNO}_{3}$. The concentrations of Fe were measured by inductively coupled plasma atomic emission spectrometry (ICP/AES; ICPE-9000, Shimadzu, Kyoto, Japan). The concentration of particulate $\mathrm{Fe}$ ( $\mathrm{P}-\mathrm{Fe})$ was estimated using the same methods as that used for measuring the $\mathrm{P}-\mathrm{P}$ concentration.

\subsection{Data Processing}

Statistical analysis of the data was performed with Microsoft Excel 2016

Table 2. The two conventional methods of measuring available P: Bray No. 2 method and Truog method.

\begin{tabular}{cc}
\hline Methods & Extraction procedure \\
\hline \multirow{2}{*}{ Bray No. 2} & $0.03 \mathrm{~mol} / \mathrm{L} \mathrm{NH}_{4} \mathrm{~F}+0.1 \mathrm{~mol} / \mathrm{L} \mathrm{HCl}$, \\
& 1 min shaking by hand, \\
& soil:extractant $=1: 20(\mathrm{w} / \mathrm{v})$ \\
Truog & $1 \mathrm{mmol} / \mathrm{L} \mathrm{H}_{2} \mathrm{SO}_{4}$, \\
& 30 min shaking $(165 \mathrm{rpm})$, \\
& soil:extractant $=1: 200(\mathrm{w} / \mathrm{v})$ \\
\hline
\end{tabular}


(Microsoft, San Francisco, CA, USA). In evaluation of the relationships among various concentration pairs, coefficient of determination $\left(R^{2}\right)$ and $p$ value were used.

\section{Results and Discussion}

\subsection{Changes in the Chemical Forms of $P$ in Soil Submerged under Water}

Little detection of Ex-P and little fluctuation of Min-P or Res-P occurred during the experiment period.

Approximately $60 \%$ of $\mathrm{P}$ in the soil existed steadily as Fe-Mn-P even within 7 days, which showed that more than half of $\mathrm{P}$ in the soil are absorbed or bound to $\mathrm{Fe}$ - and/or Mn-oxides. Thereafter, a comparatively steep decrease in Fe-Mn-P occurred 7 - 14 days from start of the experiment, whereas Org-P concentration increased in response to the decrease in Fe-Mn-P. This result showed the transformation in the chemical forms from Fe-Mn-P to Org-P, probably due to the transition of the soil redox status during this period. As shown in Figure 2, the value of Eh decreased drastically from $476 \mathrm{mV}$ to $-184 \mathrm{mV}$ in 7 days; subsequently, it decreased to approximately $-220 \mathrm{mV}$ in 28 days. Eventually, the value was almost stable at $-220 \mathrm{mV}$ until the end of the experiment, which showed that the fluctuation of the redox state from the aerobic condition to anaerobic condition is completed in a week.

It was reported that the reduction of $\mathrm{Fe}$ in the anaerobic condition of the soil

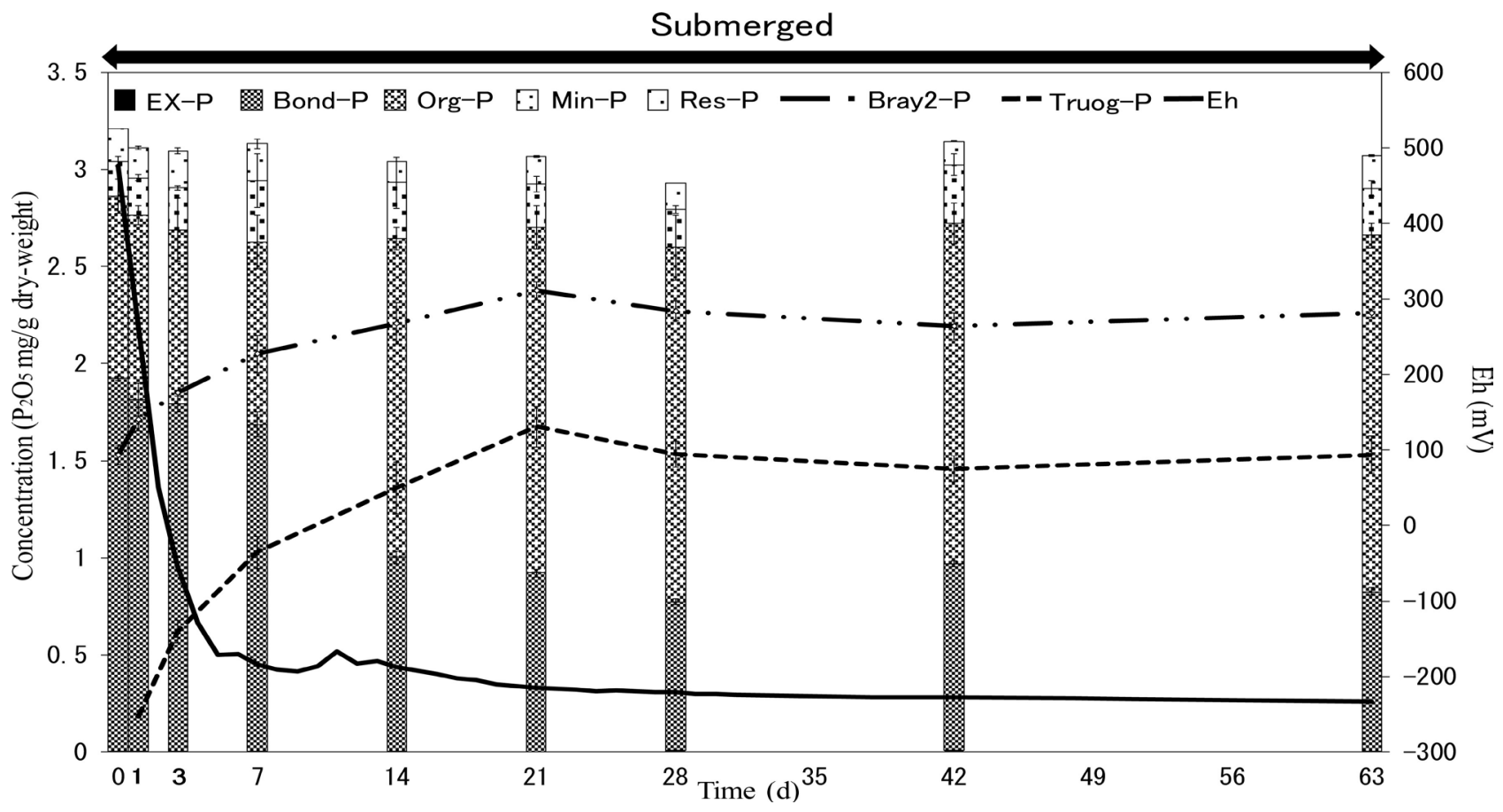

Figure 2. Concentrations of $\mathrm{P}$ and the voltage of Eh in the soil during the experimental period. The fluctuations of each $\mathrm{P}$ fraction, available $\mathrm{P}$, and ORP with time in the incubation experiment without drainage. The concentrations of $\mathrm{P}$ in the soil were expressed as $\mathrm{P}_{2} \mathrm{O}_{5} \mathrm{mg} / \mathrm{g}$ dry-weight. Error bars represent standard deviation $(\mathrm{n}=3)$. 
resulted in dissolution of oxides followed by the release of Fe and sorbed $\mathrm{P}$ by several studies (e.g., Kjaergaard et al. [18], Forsmann et al. [19]). Thus, the P bound to Fe oxide (i.e., Fe-Mn-P) was leached into the pore water, resulting in the decrease of concentrations of Fe-Mn-P. Eventually, the dissolved P appeared to be sorbed on the organic matter, so that the chemical form of $\mathrm{P}$ was categorized in Org-P. Importantly, it was demonstrated that the soil redox condition is the important factor determining the speciation of $\mathrm{P}$.

Both Bray2-P and Truog-P increased after 21 days from the onset of treatment by approximately $30 \%$ and $900 \%$, respectively, implying that the bioavailability of soil P to plant increased. This increase in bioavailability probably resulted from the release of dissolved $\mathrm{P}$ under the anaerobic condition during submergence. After the increase of Bray2-P and Truog-P, both the values remained constant.

In addition, both of Bray2-P and Truog-P exceeded the sum of Ex-P and Fe-Mn-P from 14 days of the incubation, which showed that a portion of Org-P was also contained in available $\mathrm{P}$. It is known that Bray2-P includes inorganic $\mathrm{P}$; calcium-associated $\mathrm{P}$, and some of the $\mathrm{Al}$ - and Fe-associated $\mathrm{P}$, and that Truog-P includes acid-soluble P; and calcium- and magnesium-associated P [16]. Evidently, some of the Fe-Mn-P was transformed into the chemical forms of $\mathrm{P}$ sorbed to $\mathrm{Al}$ and $\mathrm{Fe}$ (oxy)hydroxides categorized in Org-P. Alternatively, it was expected that both indexes of available $\mathrm{P}$ contain some parts of $\mathrm{P}$ sorbed on organic matters.

\subsection{Changes in the Chemical Forms of $P$ in the Soil with Drainage}

Similar to the incubation experiment without drainage, little fluctuations in the concentration of Ex-P, Min-P, and Res-P were observed throughout the experiment, as illustrated in Figure 3.

Total P (=Ex-P + Fe-Mn-P + Org-P + Min-P + Res-P) concentration in the soil appeared to be almost constant. Thus, during the incubation period, a complementary fluctuation between Fe-Mn-P and Org-P occurred, which implied that these two forms easily interconverted. The relation of the sum of the three chemical forms (i.e., Ex-P, Fe-Mn-P, and Org-P) with Bray2-P or Truog-P before the drainage were similar to those in the experiment without drainage, which confirmed that bioavailable forms were included in these three chemical forms during the submergence period even in the experiment with the drainage. However, unlike the experiment without drainage, both Bray2-P and Truog-P decreased after 7 days from the beginning of the drainage period, which indicated the decline of $\mathrm{P}$ availability due to drainage followed by the dryness of the soil. In addition, the extent of decrease of Bray2-P was different from that of Truog-P. As shown in Figure 4, the ratio of Truog-P/Bray2-P was constant at approximately 0.70 throughout the incubation experiment without drainage. On the other hand, the ratio decreased from 0.60 to 0.38 via the drainage (Figure 4). Moreover, the value of Truog-P was below the sum of Ex-P and Fe-Mn-P, which 


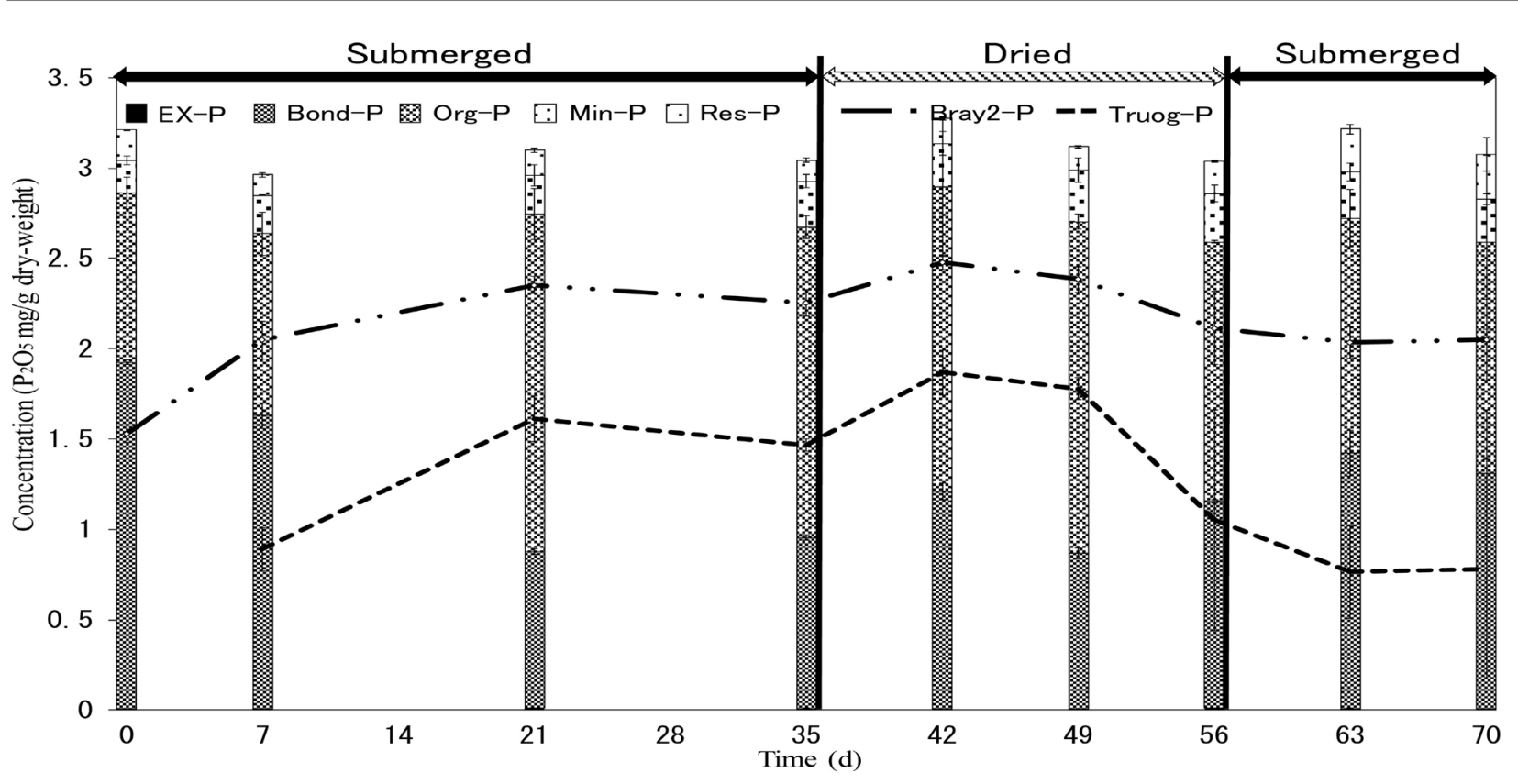

Figure 3. Fluctuations in the concentrations of each $\mathrm{P}$ fraction and available $\mathrm{P}$ with time in the incubation experiment with drainage. The concentrations of $\mathrm{P}$ in the soil were expressed as $\mathrm{P}_{2} \mathrm{O}_{5} \mathrm{mg} / \mathrm{g}$ dry-weight. Error bars represent standard deviation $(\mathrm{n}=3$ ).

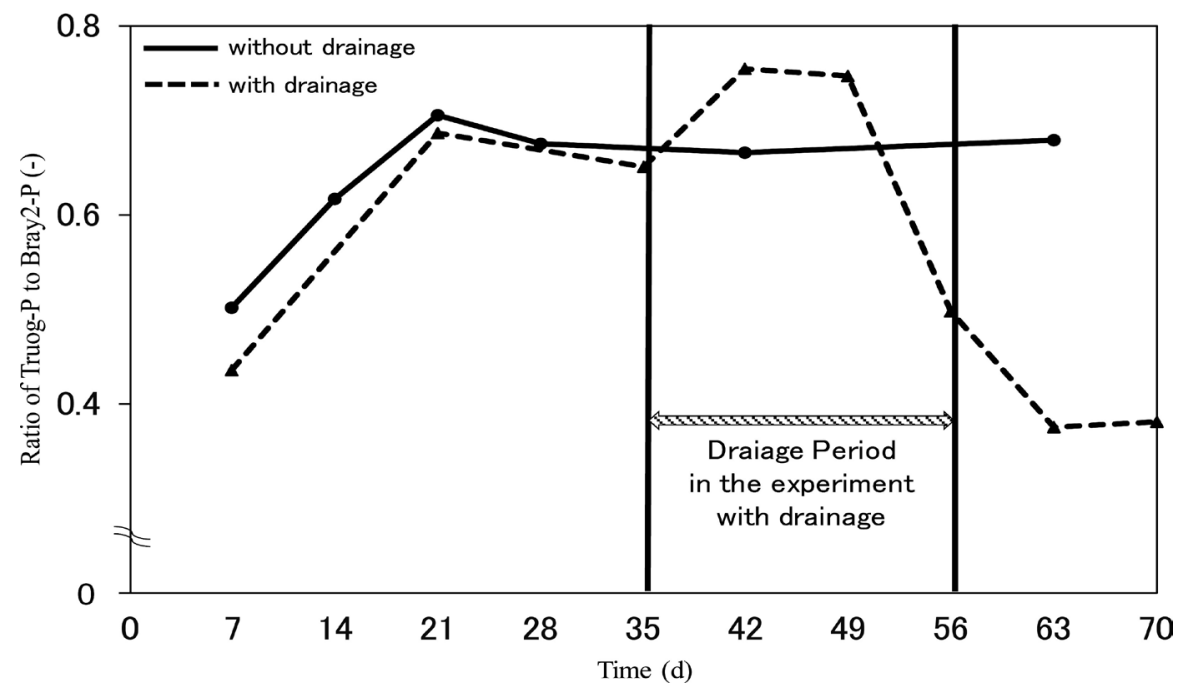

Figure 4. The change in the ratio of Truog-P to Bray2-P with time during the incubation experiment.

should be included in available $\mathrm{P}$ (Figure 3). These results show that some new chemical forms of $\mathrm{P}$, which are contained in Bray2-P but not in Truog-P, may be generated during the change in the soil redox condition. Therefore, it is indicated that the change in the soil state may sometimes impair the evaluation of available $\mathrm{P}$ by a conventional method.

\subsection{Concentrations of $P$ and Fe in the Water Used for Flooding in Each Incubation Experiment}

In the experiment without drainage, a peak of T-P concentration of $6.9 \mathrm{P}_{2} \mathrm{O}_{5}$ $\mathrm{mg} / \mathrm{L}$ was found after 7 days from the submerged soil (Figure 5). Thereafter, the 

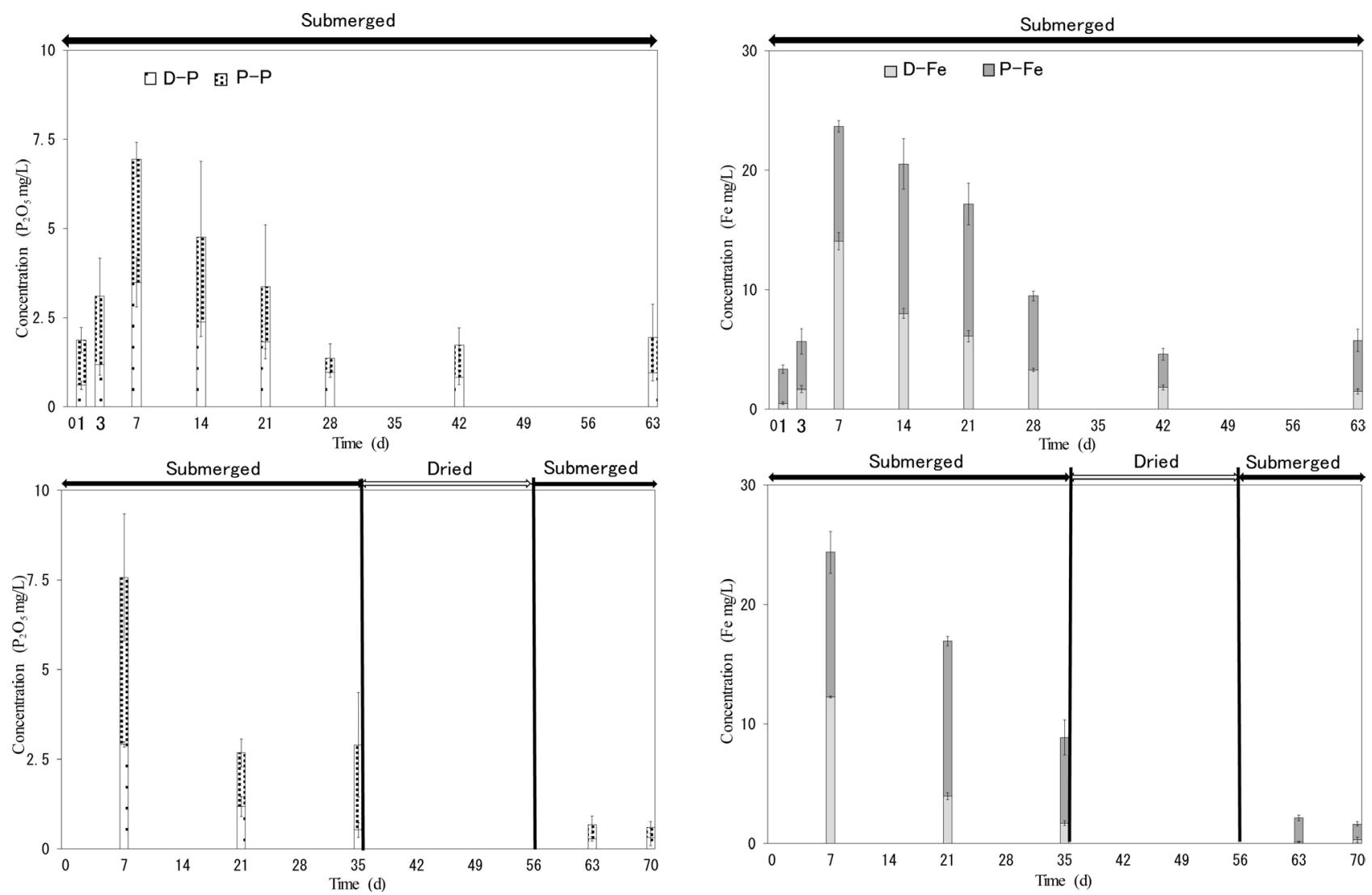

Figure 5. The changes in D-P, P-P, D-Fe, and P-Fe concentrations with time in each incubation experiment. The concentration of each form of $\mathrm{P}$ and Fe in the water is expressed as $\mathrm{P}_{2} \mathrm{O}_{5} \mathrm{mg} / \mathrm{L}, \mathrm{Fe} \mathrm{mg} / \mathrm{L}$, respectively. Error bars represent standard deviation $(\mathrm{n}=$ 3).

T-P concentration decreased gradually until 28 days, but it remained almost unchanged subsequently. The fluctuation pattern of $\mathrm{P}$ concentration was similar to that of Fe; therefore, the correlation coefficient between them was high $\left(\mathrm{R}^{2}=\right.$ $0.76, \mathrm{p}=0.0045)$. Thus, it indicated that $\mathrm{P}$ had a similar pattern of leaching and precipitation as that of Fe in the soil. The increases of T-P, T-Fe, D-P, and D-Fe concentrations in the water used for flooding resulted from the releases of $\mathrm{P}$ and $\mathrm{Fe}$ in the soil. As shown in Figure 4 of Eh, the redox condition in the soil changed to anaerobic condition in a week. As mentioned previously, the subsequent release of $\mathrm{P}$ and Fe probably contributed to their increase in the water used for flooding.

The decreases in these two concentrations probably resulted from the transformation to some insoluble forms by the combination of P and Fe. Kyuma [20] reported that dissolved Fe could be leached into the relatively oxic subsoil, where it could be re-oxidized and re-precipitated. Moreover, Fe oxides are reported to have a high capacity to bind $\mathrm{P}$ [21].

Additionally, in the experiment with drainage, although the maximum concentrations of $\mathrm{P}$ and $\mathrm{Fe}$ occurred after 7 days from the start of incubation, as in the experiment without drainage, the leaching 7 days after the re-submergence (i.e., after 63 days from the start) was much less. This could be attributed to the 
inadequate reduction (re-dissolution) on the soil surface, where the anaerobic state was weak. However, the detailed mechanism of the behavior of $\mathrm{P}$ and $\mathrm{Fe}$ in the water used for flooding is not understood to date. Further studies should address this issue in future.

\section{Conclusions}

In the present study, the incubation experiments with/without drainage provide novel insights into the fluctuation in $\mathrm{P}$ species and availability of $\mathrm{P}$ in the paddy field soil. The speciation of $\mathrm{P}$ in soil using the sequential extraction showed transformation in the chemical forms from Fe-Mn-P to Org-P. This was probably caused by the release of $\mathrm{P}$ from $\mathrm{Fe}$ and $\mathrm{Mn}$ oxide particles by the reduction and dissolution of Fe under anaerobic conditions. Eventually, some of the released $\mathrm{P}$ was probably formed into compounds, which were categorized as Org-P. We concluded that the anaerobic status in soil played some important roles in the efficient consumption of $\mathrm{P}$.

In both the incubation experiments, the transformation of the chemical forms of $\mathrm{P}$ in the soil occurred only between Fe-Mn-P and Org-P., In addition, these experiments demonstrated that these two chemical forms of $\mathrm{P}$ are easily interconverted owing to changes in the soil redox status.

Based on the observation of $\mathrm{P}$ available to plants, Bray2-P and Truog- $\mathrm{P}$, the availability of $\mathrm{P}$ was increased in soil submerged for 21 days. Thereafter, two different values were almost constant, which indicated that the availability was stable as long as the soil was submerged, i.e., under anaerobic conditions. However, in the incubation experiment with drainage, Bray2-P was almost constant throughout the experimental period, whereas a drastic decrease in Truog-P occurred during the drainage period, indicating that some chemical form(s) of $\mathrm{P}$ other than those included in Truog-P may be generated.

Comparison of the values of available $\mathrm{P}$ and those of the concentrations in each chemical form showed that available $\mathrm{P}$ concentrations often exceeded the sum of Ex-P and Fe-Mn-P. This indicated that available P may include some Org-P as well as Ex-P and Fe-Mn-P, which are likely to be transferred in soil and easily absorbed by plants. Further research is needed for the identification of the chemical forms of available P.

\section{Conflicts of Interest}

The authors declare no conflicts of interest regarding the publication of this paper.

\section{References}

[1] Sugito, T. and Shinano, T. (2013) Estimating Phosphorus Availability in Andosols using Soil Biomass Phosphorus as an Indicator. JARQ, 47, 347-351. https://doi.org/10.6090/jarq.47.347

[2] Cordell, D., Drangert, J.O. and White, S. (2009) The Story of Phosphorus: Global Food Security and Food for Thought. Global Environmental Change, 19, 292-305. 
https://doi.org/10.1016/j.gloenvcha.2008.10.009

[3] Daniel, T.C., Sharpley, A.N. and Lemunyon, J.L. (1998) Agricultural Phosphorus and Eutrophication: A Symposium Overview. Journal of Environmental Quality, 27, 251-257. https://doi.org/10.2134/jeq1998.00472425002700020002x

[4] Chen, M. and Graedel, T.E. (2016) A Half-century of Global Phosphorus Flows, Stocks, Production, Consumption, Recycling, and Environmental Impacts. Global Environmental Change, 36, 139-152. https://doi.org/10.1016/j.gloenvcha.2015.12.005

[5] Reddy, K.R., Kadlec, R.H., Flaig, E. and Gale, P.M. (1999) Phosphorus Retention in Streams and Wetlands: A Review. Critical Reviews in Environmental Science and Technology, 29, 83-146. https://doi.org/10.1080/10643389991259182

[6] Siml, V. (2000) Phosphors in the Environment: Natural Flows and Human Interferences. Annual Review of Energy and the Environment, 25, 53-88. https://doi.org/10.1146/annurev.energy.25.1.53

[7] Olsen, S.R. and Sommers, L.E. (1982) Phosphorus. In: Page, A.L., Ed., Methods of Soil Analysis. Part 2 Chemical and Microbiological Properties, Soil Science Society of America Inc., Madison, 403-430.

[8] Kuo, S. (1996) Phosphorus. In: Sparks, D.L., Ed., Methods of Soil Analysis. Part 3 Chemical Methods, Soil Science Society of America Inc., Madison, 869-917.

[9] Chang, S.C. and Jackson, M.L. (1957) Fractionation of Soil Phosphorus. Soil Science, 84, 133-144. https://doi.org/10.1097/00010694-195708000-00005

[10] López-Piñeiro, A. and Garcia-Navarro, A. (2001) Phosphate Fractions and Availability in Vertisols of South-Western Spain. Soil Science, 166, 548-556.

https://doi.org/10.1097/00010694-200108000-00006

[11] Matsushita, H., Maruyama, H., Aomi, T. and Ishikawa, N. (1974) Silver-Silver Chloride Electrode Prepared with the Use of Molten Silver Chloride. Memoirs of Chubu Institute of Technology, 10-A, 117-122.

[12] Wilson, T.A., Amirbahman, A., Norton, S.A. and Voytek, M.A. (2010) A Record of Phosphorus Dynamics in Oligotrophic Lake Sediment. Journal of Paleolimnology, 44, 279-294. https://doi.org/10.1007/s10933-009-9403-y

[13] Psenner, R., Boström, B., Dinka, M., Petterson, K., Pucsko, R. and Sager, M. (1988) Fractionation of Phosphorus in Suspended Matter and Sediment. Archiv für Hydrobiologie: Ergebnisse der Limnologie, 30, 98-103.

[14] Bray, L.H. and Kurts, L.T. (1945) Determination of Total Organic and Available Forms of Phosphorus in Soils. Soil Science, 59, 39-45. https://doi.org/10.1097/00010694-194501000-00006

[15] Truog, E. (1930) Determination of Readily Available Phosphorus in Soils. Journal of the American Society of Agronomy, 22, 874-882. https://doi.org/10.2134/agronj1930.00021962002200100008x

[16] Nanjo, M. (2003) Kakyūtai rin. In: Dojō Hyōjun Bunseki Sokuteihō Iinkai, Ed., Dojō hyōjun bunseki sokuteihō, Hakuyusha Co. Ltd., Tokyo, 127-135 (in Japanese). [Available Phosphorus. In: Committee of Soil Standard Analysis and Measurement Method of Japanese Society of Soil Science and Plant Nutrition, Ed., Soil Standard Analysis and Measurement Method, Hakuyusha Co. Ltd., Tokyo, 127-135.]

[17] Arai, Y. and Sparks, D. (2001) ATR-FTIR Spectroscopic Investigation on Phosphate Adsorption Mechanisms at the Ferrihydrite-Water Interface. Journal of Colloid and Interface Science, 241, 317-326. https://doi.org/10.1006/jcis.2001.7773

[18] Kjaergaard, C., Heiberg, L., Jensen, H.S. and Hansen, H.C.B. (2012) Phosphorus 
Mobilization in Rewetted Peat and Sand at Variable Flow Rate and Redox Regimes. Geoderma, 173, 311-321. https://doi.org/10.1016/j.geoderma.2011.12.029

[19] Forsmann, D.M. and Kjaergaard, C. (2014) Phosphorus Release from Anaerobic Peat Soils during Convective Discharge-Effect of Soil Fe P Molar Ratio and Preferential Flow. Geoderma, 223-225, 21-32. https://doi.org/10.1016/j.geoderma.2014.01.025

[20] Kyuma, K. (2004) Paddy Soil Science. Kyoto University and Trans Pacific Press, Melbourne, Australia.

[21] Terrento, J., Schwertmann, U. and Barrón, V. (1992) Fast and Slow Phosphate Sorption by Goethite-Rich Natural Materials. Clays and Clay minerals, 40, 14-21. https://doi.org/10.1346/CCMN.1992.0400103 